\title{
Sequencing in Customs Union Formation : Theory and Application to the Eurasian Economic Union
}

\author{
Aidos Alimbekov \\ KIMEP University, Almaty, Kazakhstan \\ Eldar Madumarov \\ KIMEP University, Almaty, Kazakhstan \\ Gerald Pech \\ KIMEP University, Almaty, Kazakhstan
}

\begin{abstract}
In the model of optimal sequencing in economic integration, an agenda setter chooses between two bargaining protocols that correspond to two different integration paths. With multilateral negotiations, the union is formed immediately, whereas with sequential negotiations, a core union is formed before all other countries in the region integrate. The latter is preferred if formation of a core union has negative externalities on a candidate country. The agenda setter improves her bargaining position, but an efficiency loss from delayed integration is incurred. We demonstrate that the threat of delayed entry will not be carried out if an open-rule protocol is available, i.e., if the agenda setter can propose to form a core union and amend this proposal before it is adopted. Yet, if bargaining
\end{abstract}

\footnotetext{
* Corresponding Author: Gerald Pech; Department of Economics, KIMEP University, 2-4 Abaya, 050010 Almaty, Kazakhstan, Tel: +7 7272704349, Fax:+77272704344, email: gp@geraldpech.net.

Co-Autor: Aidos Alimbekov; Department of Economics, KIMEP University, 2-4 Abaya, 050010 Almaty, Kazakhstan, Tel: +7727270 4349, Fax: +77272704344, email: alimbekov_aidos@mail.ru.

Eldar Madumarov; Department of Economics, KIMEP University, 2-4 Abaya, 050010 Almaty, Kazakhstan, Tel: +7727270 4271, Fax: +77272704344, email: madumarov@kimep.kz.
} 
is time consuming, this result can be overturned and there may be a delay that incurs a temporary efficiency loss. Our model explains the sequential formation of the Eurasian Customs Union.

JEL Classifications: D78, F15

Keywords: Regional Integration, Sequencing, Customs Union, Bargaining Cost

\section{Introduction}

What drives economic and political integration over time? This is an old question asked by economists and political scientists. A central concern of this literature is the question of which sequences of integration moves are feasible and, if feasible, desirable or likely to happen. ${ }^{1}$ The creation of an integrating bloc often has externalities on nonmember states and puts pressure on such states to join the bloc. Examples include the extension of the European Community in 1992, the foundation of the North American Free Trade Agreement (NAFTA) following the United States (US)-Mexico Free Trade Agreement (Baldwin 1996), and, more recently, the formation of the Eurasian Customs Union, which later transformed into the Eurasian Economic Union.

Aghion, Antràs, and Helpman (2007), henceforth AAH, have proposed an agenda setter model of customs union formation ${ }^{2}$ where the existence of externalities creates strategic incentives for sequencing. Assume the agenda setter can choose from two bargaining protocols: Under a sequential bargaining procedure, a core customs union is formed in the first round and an accession candidate is invited to join in the following round. Under a multilateral bargaining procedure, all countries are invited to join during the same stage. If the core customs union has a negative (positive) externality on an accession candidate, the bargaining position of the agenda setter relative to the candidate is strengthened (weakened) under the sequential bargaining procedure. Hence, the agenda setter has preferences over the bargaining protocols or, equivalently, the order in

\footnotetext{
${ }^{1}$ For a recent overview, see Baldwin (2012).

2 Aghion, Antràs and Helpman focused on free trade agreements but suggested that their results are applicable to customs union formation. Clearly, with the more complex policy choices in a customs union, there is precisely the scope for compensation between members for which their transferable utility model is a reasonable approximation.
} 
which other countries are invited to participate in the negotiations over the formation and extension of the customs union. If the accession candidate suffers negative externalities from the formation of a core customs union, her default payoff is reduced under the sequential bargaining procedure, making it cheaper for the agenda setter to buy off the candidate. While efficiency is ultimately achieved under weak conditions, a temporary inefficiency is incurred along the sequential integration path. ${ }^{3}$

This inefficiency result, however, crucially depends on the set of available bargaining protocols. The agenda setter is forced to propose against the current status quo, so any alternative which might serve as a threat has to be turned into the current status quo before bargaining can proceed any further. This restriction can clearly affect the outcome: Assume payoffs are such that forming a core customs union with negative externalities is a credible threat. ${ }^{4}$ If such a threat could effectively be raised during the course of bargaining, it would not have to be carried out in equilibrium when all parties are rational and farsighted. The AAH model, however, assumes that such a threat cannot be raised under multilateral bargaining, where the alternative to acceptance is the status quo. The alternative of delaying the formation of the customs union is only available under sequential bargaining. Yet once the agenda setter has opted for sequential bargaining, this alternative cannot serve as a threat because delay is already part of the description of the bargaining protocol. If we allow, instead, the proposer to choose a bargaining protocol where an offer that is accepted by another accession country becomes the default outcome for the next bargaining move-a protocol that is similar to Baron and Ferejohn's (1989) open-rule protocol — the final outcome preferred by the agenda setter is immediately accepted. ${ }^{5}$ This is a fundamental result: If bargaining is frictionless, open-rule bargaining is preferred to sequential bargaining. If, however, bargaining is costly because it takes time, this result may be reversed.

Ploeckl (2010) has applied the AAH argument to the formation of the German Customs Union, where a leading country_Prussia — successively increased the size of the integrating bloc by approaching smaller states, in some cases prising them from competing blocs. On the face of it, the formation of the Eurasian Customs Union manifests many features of the German case: One country-Russia—has been the

\footnotetext{
${ }^{3}$ Gomes and Jehiel (2005) have shown that, depending on the bargaining protocol, bargaining among fully rational agents in the presence of externalities may result in inefficiencies. Acemoglu, Egorov and Sonin (2012) have noted that this result may not hold in an environment with transfers.

${ }^{4}$ Forming the core customs union is credible, i.e., it is preferred by its members to the status quo before negotiations start, if the game is superaddivitive as defined in Section III.

${ }^{5}$ This qualification has already been noted by Gomes and Jehiel (2005).
} 
driving force behind the integration project and, because of its relative size and wealth, is in a position to act as the agenda setter and to choose between different integration paths. Initially, a core customs union was formed, while a laggard country - Kyrgyzstan — was clearly negatively affected by the core customs union. A number of observers concluded after the formation of the core customs union that Kyrgyzstan would lose as much by staying out as by getting in (Pavlov 2012) or that, in the words of the Kyrgyz president Atambaev, joining the union was the lesser of two evils.

Yet, while the formation of the core customs union clearly put pressure on Kyrgyzstan, it seems plausible that in the absence of external constraints, an early accession could have been achieved with at least the same outcome for all parties involved: Kyrgyzstan, which eventually joined in 2015, had already been a candidate country before the core customs union formed in 2010. For some authors, the complications arising from the World Trade Organization (WTO) membership of Kyrgyzstan were the main problem. The membership had particularly favorable conditions for most third countries. This problem necessitated negotiations either over the terms of entry into the customs union or over the agreements with third countries (Keene 2013 and Khitakhunov et al. forthcoming). Our result suggests that while a negative externality will put pressure on the accession country, it is a necessary condition for sequential entry that bargaining is time consuming and costly. In particular, the longer it takes to finalize an agreement for the entire union relative to the time it takes to seal the accession of a candidate to the core union, the more attractive sequential formation of customs union will be.

Our study suggests that bargaining time is central to the choice between different integration paths and that bargaining therefore incurs a real cost in terms of foregone integration gains. A reduction in bargaining time, for example by implementing transition arrangements, could therefore be welfare enhancing.

To derive our results, we extend the static AAH model into a full dynamic framework by explicitly adding a time dimension. Accordingly, we reformulate the bargaining protocols of the AAH model for a dynamic framework. Like AAH, we focus on the case of three players and assume that payoffs in the integration game satisfy grand coalition superadditivity (GC superadditivity) so that forming the grand coalition is efficient. ${ }^{6}$ Most importantly, we add to the menu, giving the agenda setter the option to choose the two-stage open-rule protocol and allow for time to elapse in bargaining before the second

${ }^{6}$ We use a slightly stronger condition to derive our comparative statics result of Proposition 3. 
stage is reached.

Section II gives an overview of the literature. Section III develops a dynamic version of the AAH model. Section IV introduces different bargaining protocols and derives our results. In section V, we apply our results to the formation of the Eurasian Customs Union and the German Customs Union, that is, Zollverein. Section VI concludes.

\section{Literature Review}

Our theoretical model is based on the study by Aghion et al (2007), who present a theory of optimal sequencing in regional integration. They develop a characteristic function bargaining game where a leading country has agenda-setting power and decides between forming a union in one round of multilateral bargaining or sequentially extending a core union by adding new members. Under a relatively weak conditionthat GC superadditivity holds - the largest coalition is eventually formed. Moreover, they show that if the formation of a core union exerts negative externalities on potential accession candidates, the agenda setter proposes to form a core union before fully integrating.

Sen and Biswas (2015) share with our study a focus on explaining sequencing and also identify the restriction on available bargaining protocols as a shortcoming of the AAH study. In a static framework, they introduce a variant of the multilateral bargaining protocol, where the rejection of an offer does not result in the breakdown of negotiations but in the formation of a coalition of all who approve. They show that in the presence of positive externalities, the agenda setter will prefer the sequential bargaining protocol to their variant of the multilateral bargaining protocol; they claim that with negative externalities, the agenda setter prefers the modified protocol. ${ }^{7}$

Baldwin (2012) provided a general dynamic framework in which he addresses issues of sequencing within a theory of economic and political integration. His main interest was in identifying the dynamic mechanisms by which integration changes the conditions for further integration and, thus, results in a self-sustained process of enlargement and

\footnotetext{
7 Their analysis of the case with negative externalities appears to rest on the assumption that after receiving an offer, both responders believe with probabilility one that the other responder will accept the offer, yet it remains unclear how these beliefs can be supported in equilibrium. Details are available from the authors.
} 
deepening regional trade agreements. Although our framework explicitly incorporates a time dimension, it analyzes different sequencing choices within a stationary environment. It thus provides an important link between the atemporal AAH model and a fully dynamic framework.

A related strand of literature on sequencing has focused on the question of whether customs unions are a first step or rather a stumbling block on the path to worldwide free trade. Yi (2000) showed that worldwide free trade is a possible end point of a process of forming, extending, or merging regional preferential trading blocs. Saggi and Yildiz (2011) derived the conditions under which the availability of bilateral trade agreements facilitates the free trade outcome or is compatible with an alternative equilibrium. Yi (1997) provided the conditions under which free trade is stable and Furusawa and Konishi $(2005,2007)$ explored the stability of bilateral free trade agreements.

\section{Welfare Effects of Customs Union Formation}

We follow AAH in assuming that a country's payoff can be summarized by a payoff value $w(\Gamma, \boldsymbol{t})$, which is exclusive of transfers, and depends on the partition $\Gamma$ of the set of countries $N$ into coalitions (customs unions) and singletons. Moreover, we explicitly allow $w$ to depend on a policy vector $\boldsymbol{t}$, which comprises tariff vectors imposed by all countries. $w$ summarizes the effect of all economic and political variables influencing welfare. In Appendix 1, we suggest a specific functional form of $w$ based on Yi (1996) and Furusawa and Konishi (2005).

In general, the overall effect of forming a customs union on the welfare of its members is ambiguous: Consider the situation of a country that finds itself with increased external tariffs after joining. As imports from third countries decrease, its trade surplus improves but consumption utility is negatively affected. The trade surplus or deficit with other members of the customs union may increase or decrease as tariffs between members are reduced to zero. Yet, even if some countries experience a welfare loss from the creation of a customs union, the customs union is feasible as long as the winners can afford to compensate the losers.

We assume that costless transfers between countries are feasible, and we define $w_{S}(\Gamma, \boldsymbol{t})=\sum_{i \in S} w_{i}(\Gamma, \boldsymbol{t})$ as the aggregate welfare of coalition $S$ given a partition $\Gamma=$ 
$\left\{S_{1}, \ldots, S_{m}\right\}$ of the set of players $N$ and a policy $\boldsymbol{t}$. Focusing on the case $N=\{1,2,3\}, w$ satisfies GC superadditivity if

$$
w_{N}\left(\{N\}, \boldsymbol{t}^{\prime}\right) \geq w_{N-R}(\{N-R, R\}, \boldsymbol{t})+w_{R}(\{N-R, R\}, \boldsymbol{t})
$$

for all $R=\{i\}, i \in N$ and $R=\{\{i\},\{j\}\}, i, j \in N, i \neq j$ and some $\boldsymbol{t}^{8}{ }^{8}$ It satisfies superadditivity if the condition

$$
w_{S \cup T}\left(\{S \cup T, N-S-T\}, \boldsymbol{t}^{\prime}\right) \geq w_{S}(\{S, T, N-S-T\}, \boldsymbol{t})+w_{T}(\{S, T, N-S-T\}, \boldsymbol{t})
$$

holds for all non-overlapping subcoalitions $S$ and $T$ of $N$ and for some admissible tariff choice $\boldsymbol{t}$ ' for a customs union $S \cup T$ when its complement $N-S-T$ plays a best response. Throughout our study, we follow AAH in assuming that GC superadditivity holds. The stronger condition of superadditivity is imposed to derive our comparative result of Proposition 3.

The following is a sufficient set of conditions for aggregate welfare to be superadditive: Political benefits and costs do not punish integration, each country is characterized by a representative consumer with a quasi-linear utility function and taste for variety, each country produces one industrial good and tariff revenue and profits are distributed to the consumer (Yi 1996).

\section{Bargaining over Customs Union}

This section extends the model of Aghion et al (2007). We confine ourselves to their original three-player model to which we add an explicit temporal structure. For simplicity, we assume that players have an identical discount factor $\delta<1$ with which they discount their future utility flow $w_{i}$. Let $W_{i}=\frac{\delta}{1-\delta} w_{i}$ denominate the present value of an infinite utility flow $w_{i}$. Player 1 is the agenda setter and 2 and 3 are followers. Each

\footnotetext{
${ }^{8}$ Unlike AAH, we include equality and state in Proposition 1 that the grand coalition may form to cover the case when the agenda setter is indifferent. Note that for the results it is sufficient that GC superadditivity holds for all cases where the "integrating core" $N-R$ includes the agenda setter.
} 
round of the bargaining game consists of an offer by the agenda setter and decisions to accept or reject by the responders. An offer consists of a coalition that the agenda setter wishes to form and the policy vector she wants to implement for this coalition. ${ }^{9}$ If an offer is rejected, a default outcome is realized.

Our, and ultimately AAH's, argument rests on the assumption that forming a core customs union and selecting a policy vector for it has negative externalities on the leftout country and will affect the left-out country's bargaining position when negotiating over accession to the union. ${ }^{10}$ In this situation, the agenda setter could be tempted to announce a policy that minimizes the payoff of the left-out country. If the left-out country assumes that in the absence of an agreement, this minimizing policy is going to remain in place in the future, it will perceive its bargaining position to be weakened accordingly. The policy, however, is not credible if policies, other than coalition structures, can be renegotiated at no cost. ${ }^{11}$ Henceforth, we shall make the assumption that a policy announcement for any coalition has to be credible, i.e., that it maximizes short-term total welfare for the customs union.

\section{A. The basic multilateral bargaining model: closed-rule protocol}

For the multilateral bargaining scenario, we assume that there is one round of bargaining where the agenda setter makes an offer for a coalition. If the offer is rejected by at least one player, the default outcome is realized for an indefinite length of time. The default outcome is the status quo coalition structure $\Gamma^{0}$ consisting of singletons and associated with welfare levels $W_{i}\left(\Gamma^{0}, t^{0}\right), i=1,2,3$. To introduce some terminology for later reference, we call this bargaining protocol a closed-rule protocol, following Baron and Ferejohn (1989). ${ }^{12}$ In equilibrium, the agenda setter has to offer each responder their default payoff so that she herself realizes the residual payoff. Because of superadditivity, the agenda setter cannot do better than making an offer to the grand coalition, so her payoff is

\footnotetext{
${ }^{9}$ For concreteness, we assume that $l$ is a Stackelberg leader and a nonmember country plays its best response.

${ }^{10}$ Saggi, Woodland and Yildiz (2013) demonstrated in a symmetric three-country model with linear demand and competion between export countries that formation of a customs union between two countries results in a worse outcome for the left-out country than a multilateral agreement.

${ }^{11}$ Renegotiations may take the form of the agenda setter offering a policy vector and a transfer payment as a take-it-or-leave-it offer against the status quo policy.

${ }^{12}$ This is also the bargaining protocol underlying the analysis of Gomes and Jehiel (2005) to which AAH refer.
} 


$$
\Pi^{\text {Mult }}=W_{N}\left(\Gamma^{N}, \boldsymbol{t}\right)-\sum_{i \in\{2,3\}} W_{i}\left(\Gamma^{0}, \boldsymbol{t}^{0}\right)
$$

which is the total payoff for the grand coalition $N, W_{N}\left(\Gamma^{N}, \boldsymbol{t}\right)$, after paying all other members their standalone value $W_{i}\left(\Gamma^{0}, \boldsymbol{t}^{0}\right)$. If the game exhibits superadditivity, $\Pi^{\text {Mult }}$ is at least as great as the agenda setter's standalone payoff $W_{1}\left(\Gamma^{0}, \boldsymbol{t}^{0}\right)$ and forming a customs union by multilateral bargaining is feasible.

\section{B. Sequential bargaining}

In the case of sequential bargaining, the agenda setter approaches one of the other countries first - we assume that this is country 2 - and makes an offer. If the offer is rejected, the default outcome is realized, which is the coalition structure $\Gamma^{0}$ with associated welfare levels $W_{i}\left(\Gamma^{0}, \boldsymbol{t}^{0}\right), i=1,2,3$. If the offer is accepted, the coalition is formed, resulting in the coalition structure $\Gamma^{\prime}=\{\{1,2\},\{3\}\}$ with welfare levels $W_{i}\left(\Gamma^{\prime}, t^{\prime}\right)$ where $\boldsymbol{t}^{\prime}$ is the credible policy proposal vector for coalition $\{1,2\}$.

In the next round of the game country 3 is approached and an offer is made. We assume that if the new offer includes country 2 as a coalition member, it has the right to veto the offer. ${ }^{13}$ If the offer is rejected or vetoed, the status quo coalition structure $\Gamma^{\prime}$ is realized. The bargaining moves are illustrated in Figure 1, where we assume that the first move is a procedural move by which the agenda setter decides whether she wants to follow sequential negotiations by making an offer to 2 first or to follow multilateral negotiations by making an offer to $\{2,3\}$.

Clearly, the intended interpretation of the bargaining moves in the AAH model is that forming a coalition takes time and the core customs union is actually formed. We, therefore, assume that after the first proposal has been accepted or rejected, this state prevails for one period, with utility enjoyed during this period evaluated at $\delta w_{i}=(1-\delta) W_{i}{ }^{14}$ After the agenda setter has submitted her second proposal in period two, the utility flow associated with rejecting or accepting the proposal is realized indefinitely.

Assume a policy proposal $\boldsymbol{t}^{\prime}$ together with coalition structure $\Gamma^{\prime}=\{\{1,2\},\{3\}\}$ has

\footnotetext{
${ }^{13}$ AAH make the alternative assumptions that the agenda setter can commit to guarantee an outcome or that she offers a conditional transfer.

${ }^{14}$ We essentially assume that there is a constant utility flow that is continuously discounted at the discount rate $r=1 / \delta-1$, see Appendix 2 for details.
} 
been accepted by 2 in the first period. So 1 needs to offer 2 and 3 their respective default payoffs $W_{2}\left(\Gamma^{\prime}, \boldsymbol{t}^{\prime}\right)$ and $W_{3}\left(\Gamma^{\prime}, \boldsymbol{t}^{\prime}\right)$ to accept forming the grand coalition. In the first period, 1 needs to offer 2 her default payoff $W_{2}\left(\Gamma^{0}, t^{0}\right) .{ }^{15}$ The agenda setter receives the discounted residual payoff

$$
\Pi_{1}^{\text {Seq }}=(1-\delta)\left[W_{\{1,2\}}\left(\Gamma^{\prime}, \boldsymbol{t}^{\prime}\right)-W_{2}\left(\Gamma^{0}, \boldsymbol{t}^{0}\right)\right]+\delta\left[W_{N}\left(\Gamma^{N}, \boldsymbol{t}\right)-W_{2}\left(\Gamma^{0}, \boldsymbol{t}^{0}\right)-W_{3}\left(\Gamma^{\prime}, \boldsymbol{t}^{\prime}\right)\right]
$$

where $\boldsymbol{t}$ is the credible policy vector for the grand coalition, which coincides with the credible policy in Equation (3): Policies in $\boldsymbol{t}$ only depend on the coalition structure and not on the payoff distribution as any transfer is lump sum and not included in $t$. By GC superadditivity, the term in the second bracket on the left-hand-side of Equation (4) is positive and the agenda setter wants to form the grand coalition when the core customs union has formed in the first step. Yet, it is unclear whether the core custom union is formed or the agenda setter prefers to maintain the status quo partition $\Gamma^{0}$.

While under superadditivity, the core customs union is preferred to the status quo partition $\Gamma^{0}$, this is not ensured by assuming GC superadditivity alone, and the grand coalition may fail to form for $\delta$ sufficiently small, qualifying the result obtained by AAH in a static environment.

Proposition 1: If superadditivity holds, the grand coalition may form under multilateral and sequential bargaining. If GC superadditivity holds but superadditivity does not, sequential (multilateral) bargaining may fail to be a path (is still a path) to forming the grand coalition.

\footnotetext{
${ }^{15}$ As there are maximally two rounds of bargaining, after a rejection in the first period, the agenda setter has to offer the grand coalition in the second period where all players other than the agenda setter realize their default payoff from remaining in $\Gamma^{0}$.
} 
Figure 1. Multilateral versus sequential bargaining

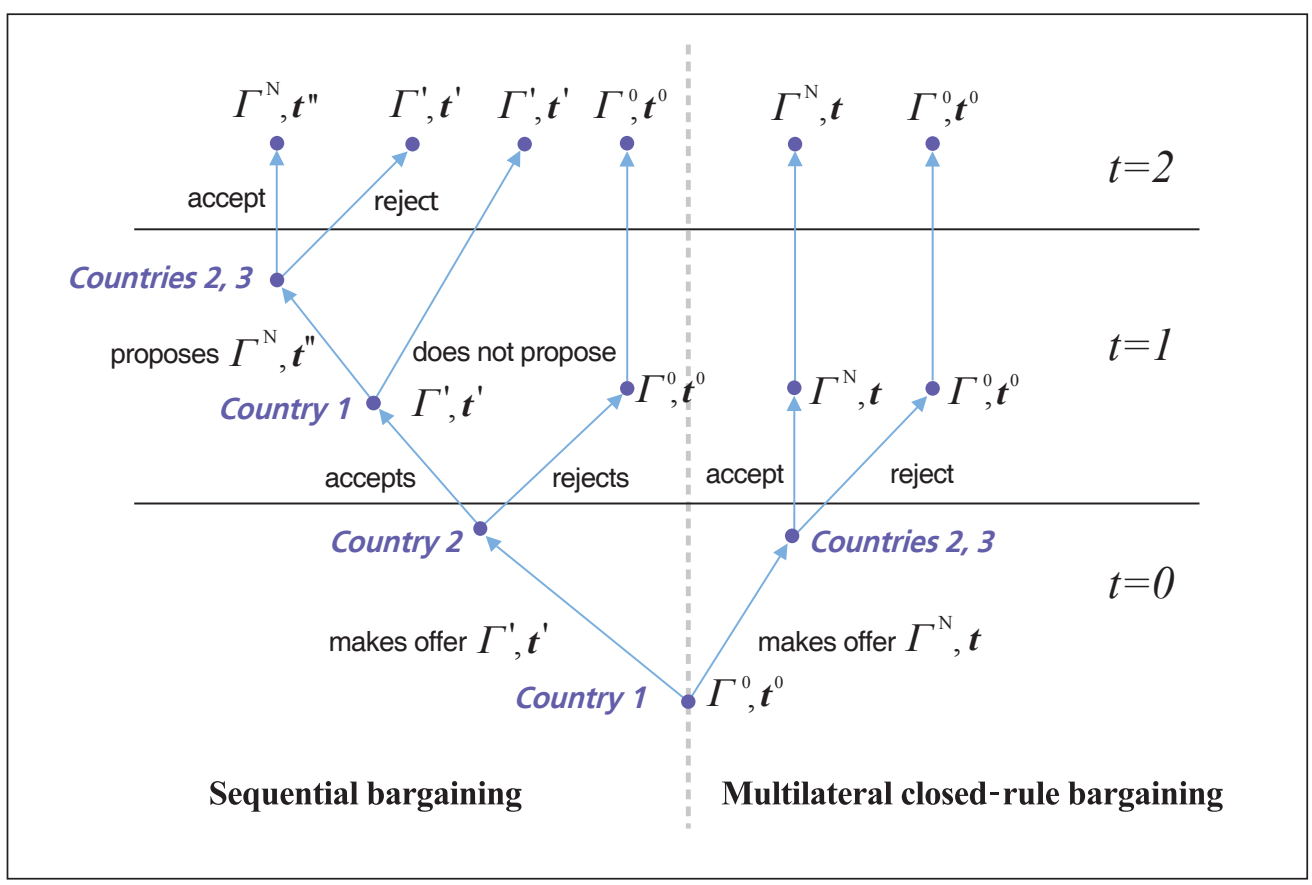

(Note) Figure 1 depicts the sequence of moves under sequential bargaining and multilateral bargaining. Under sequential bargaining the core customs union with $\left(\Gamma^{\prime}, \boldsymbol{t}^{\prime}\right)$ is offered in $t=0$ and the full union with $\left(\Gamma^{N}, \boldsymbol{t}^{\prime \prime}\right)$, exploiting the externality, may be offered in $t=1$. Under multilateral bargaining the full union $\left(\Gamma^{N}, \boldsymbol{t}\right)$ is offered in $t=0$. The default outcome is $\left(\Gamma^{0}, t^{0}\right)$.

(Source) Authors' creation, based on Aghion et al (2007).

Note that once the core customs union has formed, possibly by mistake, under the sequential bargaining institution, the agenda setter still prefers the grand coalition to form under GC superadditivity. Comparing Equation (3) and Equation (4) shows that the agenda setter is better off under sequential than multilateral bargaining if

$$
(1-\delta)\left[W_{N}\left(\Gamma^{N}, \boldsymbol{t}\right)-W_{3}\left(\Gamma^{0}, \boldsymbol{t}^{0}\right)-W_{\{1,2\}}\left(\Gamma^{\prime}, \boldsymbol{t}^{\prime}\right)\right]<\delta\left[W_{3}\left(\Gamma^{0}, \boldsymbol{t}^{0}\right)-W_{3}\left(\Gamma^{\prime}, \boldsymbol{t}^{\prime}\right)\right]
$$

The expression in square brackets on the left-hand side of this inequality is the gain or loss from not forming the grand coalition in the first period in the absence of externalities. It may be positive or negative. It may be negative because GC superadditivity only requires that the full union beats all other partitions but it does not state that joint payoffs for all subcoalitions formed of members of the integrating bloc are non-decreasing along 
a path towards forming the full union. ${ }^{16}$ The expression in square brackets on the righthand side of this inequality is the absolute value of the externality which 3 suffers if the coalition of 1 and 2 forms. For $\delta \rightarrow 1$, the externality term dominates and the inequality collapses to $W_{3}\left(\Gamma^{\prime}, \boldsymbol{t}^{\prime}\right)<W_{3}\left(\Gamma^{0}, \boldsymbol{t}^{0}\right)$, which is fulfilled whenever forming a coalition between 1 and 2 has a negative externality on country 3 . Thus, we obtain the AAH result in the limit.

Proposition 2: If patience exceeds some critical level $\underline{\delta}<1$ and there are negative coalition externalities from forming a smaller union on at least one potential entrant, the agenda setter prefers sequential negotiations over multilateral bargaining.

Hence, we predict sequencing when the efficiency loss that the agenda setter suffers is smaller than her long-term gain from realizing a better bargaining outcome. Clearly, any such result raises the question of why agents are unable to agree on a Pareto-better outcome and why a scenario that represents a credible threat may unfold in equilibrium.

\section{Multilateral bargaining: open-rule protocol}

Baron and Ferejohn (1989), in their seminal study, considered an open-rule bargaining protocol as an alternative to a closed-rule protocol in legislative decision making. ${ }^{17}$ With an open rule, a proposer may make an amendment to the proposal on the floor orby moving the previous question - she may force a vote on the proposal. Making an amendment results in moving to the next legislative session. To match the open-rule protocol to a bargaining situation with highly unequal bargaining power, we need to introduce some assumptions: Only the agenda setter can make or amend a proposal, i.e., her selection probability as a proposal maker is 1 in each round. Proposals are accepted if the coalition that is included in this proposal accepts the proposal. Moreover, the proposal on the floor, once accepted by the coalition that it includes, becomes the status quo that any amendment is voted against. By this last assumption, the status quo assumes the role of default outcome from continuing bargaining in the Baron-Ferejohn model. This bargaining protocol allows the agenda setter to make a proposal that may later be

\footnotetext{
${ }^{16}$ Assume $W^{N}=\Sigma_{i=1,2,3} W_{i}\left(\Gamma^{0}, \boldsymbol{t}^{0}\right)$ and $W_{\{1,2\}}>W_{1}+W_{2}$. In this case, the core union may be stable but with GC superadditivity $l$ wants to exploit the externality on 3 to form the grand coalition.

${ }^{77}$ The open rule protocol with no bargaining frictions coincides with a general spot contract discussed in Gomes and Jehiel (2005), i.e., in the scenario where a contract is not rejected if it is accepted by a subset of agents.
} 
amended within the ongoing bargaining process rather than actually implementing it. Effectively, this enables the agenda setter to make a threat that she does not have to carry out if the other party concedes.

As a measure of bargaining frictions in negotiations, we define a variable $s$ that measures the time elapsed between two rounds of bargaining with $s=1$ in the case where bargaining takes as much time as the formation of the customs union in the sequential bargaining scenario and $s=0$ in the case where bargaining is frictionless and takes no time at all. ${ }^{18}$

Bargaining takes place as follows (see Figure 2): The agenda setter makes an offer against the default outcome $\left(\Gamma^{0}, \boldsymbol{t}^{0}\right)$. She has to choose between offering the grand coalition or to offer 2 the core customs union $\left(\Gamma^{\prime}, t^{\prime}\right)$. Recall that $t^{\prime}$ is the credible policy proposal that maximizes aggregate payoff of for the coalition of 1 and 2 .

In the case where she offers the grand coalition, the offer is either accepted, in which case $\left(\Gamma^{N}, \boldsymbol{t}\right)$ is realized with corresponding payoff $\Pi^{\text {Mult }}$ and no amendment is proposed, or the offer is rejected, in which case the status quo prevails throughout. If she offers $\left(\Gamma^{\prime}, \boldsymbol{t}^{\prime}\right)$ and it is accepted, the agenda setter has to decide in $t=1$ whether to make an amendment to this proposal, i.e., propose the grand coalition or to implement the already-accepted core customs union. If she makes an amendment, she moves to the next bargaining session. Meanwhile, the core customs union is not implemented and the status quo prevails for a time period of length $s$. If the offer $\left(\Gamma^{N}, t^{\prime \prime}\right)$ is accepted, it is implemented in $t=1+s$, otherwise $\left(\Gamma^{\prime}, \boldsymbol{t}^{\prime}\right)$ prevails.

In equilibrium, all offers are accepted and, along the path where an amendment can be made, GC superadditivity ensures that the agenda setter can do no better than to propose the amendment. Thus, solving the game comes down to solving the decision problem of the agenda setter whether to choose the two-step procedure or to initially propose the grand coalition. With negative externalities, the long-term payoff is greater with the two-step procedure, but it has to be traded against spending time in bargaining during which the agenda setter only receives her default payoff.

If players are sufficiently patient, the two-step procedure will be selected under openrule bargaining. Moreover, we can compare the scope for open-rule bargaining to the sequential bargaining model introduced above. Both procedures result in the same longterm payoff - at least if the two-step procedure is selected under an open rule- but

\footnotetext{
${ }^{18} s$ is the time it takes to negotiate a separate agreement with one country rather than reaching an agreement in the first round of bargaining under the open rule or closed rule (multilateral) bargaining protocol. This notion of $s$ largely captures the bargaining situation encountered in our case study in Section V. A.
} 
while time spent with the smaller short-term payoff may be shorter under the open-rule protocol, the short-term payoff is lower under the open-rule protocol. In the appendix, we show that the following proposition characterizes the decisions of the agenda setter:

Proposition 3: Assume that superadditivity holds and that forming a coalition of two has negative externalities on a potential entrant. There is some critical value $s^{*}(\delta) \in(0,1)$ such that given $\delta$, the agenda setter strictly prefers the open-rule bargaining protocol to sequential bargaining if $s<s^{*}$. For $\delta$ sufficiently high and s sufficiently low, the agenda setter prefers open-rule bargaining over all other bargaining institutions, this is particularly the case when bargaining is frictionless (i.e., $s=0$ ), irrespective of $\delta$. Sequential bargaining is preferred for $s$ sufficiently large and $\delta$ sufficiently low.

Proof: See Appendix 2.

Figure 2. Bargaining under an open-rule protocol

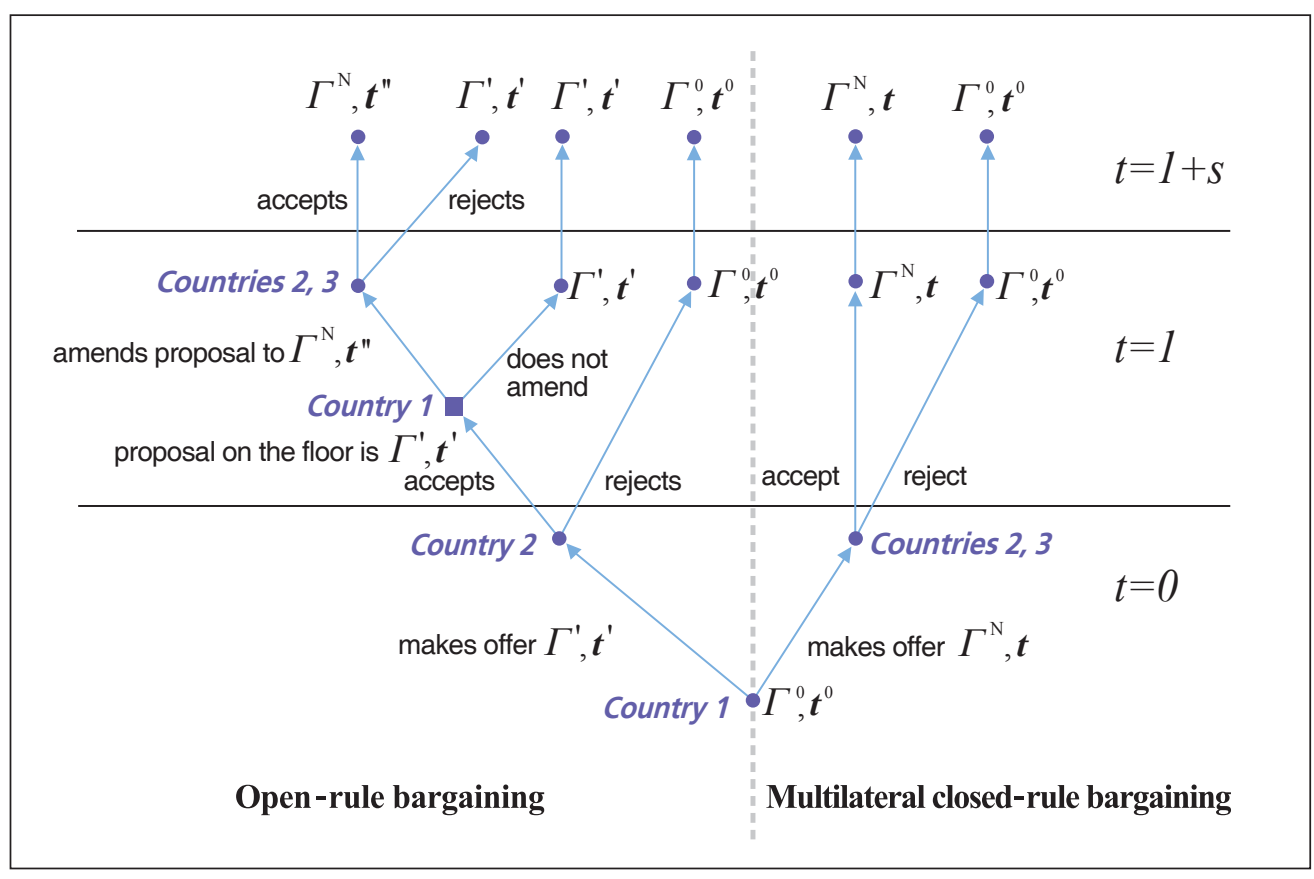

(Note) Figure 2 depicts the sequence of moves under the open-rule protocol and closed-rule multilateral bargaining. Under the open-rule protocol the core customs union with $\left(\Gamma^{\prime}, t^{\prime}\right)$ is offered in $t=0$ and becomes the proposal on the floor in $t=1$. It may be amended into the proposal of the full union with $\left(\Gamma^{N}, \boldsymbol{t}^{\prime \prime}\right)$, exploiting the externality and coming into effect in $t=1+s$. Under multilateral closed-rule bargaining the full union with $\left(\Gamma^{N}, \boldsymbol{t}\right)$ is offered immediately. The default outcome is $\left(\Gamma^{0}, \boldsymbol{t}^{0}\right)$.

(Source) Authors' creation. 
Open-rule bargaining may reduce the efficiency loss involved in the sequential coalition formation process: If bargaining is frictionless $(s=0)$ and there are negative externalities, the agenda setter prefers the open-rule bargaining protocol to sequential bargaining and to multilateral bargaining: The open-rule protocol allows the agenda setter to credibly announce the threat of forming the core customs union coalition, but she does not have to execute the threat to ensure a higher payoff for herself. Sequential bargaining is preferred when $s$ is large and the cost of having to wait for the grand coalition to form is relatively small compared with forming the core customs union immediately, i.e., for $\delta$ sufficiently small.

If GC superadditivity holds but superadditivity does not, open-rule bargaining is generally preferred to sequential bargaining. ${ }^{19}$ In this case, the agenda setter's standalone value is greater than her value in the core customs union. Thus, it is an advantage for her not to have to form it and there is no tradeoff involved in choosing open-rule bargaining.

Overall, an efficiency loss from delayed integration is realized although the agenda setter-as residual claimant-has an incentive to choose the most cost-efficient bargaining regime as long as this does not affect her position to exploit the externality on the accession candidate.

\section{Applications}

\section{A. Eurasian Customs Union}

The formation of the Eurasian Customs Union is the most recent attempt at economic integration in the post-Soviet space. ${ }^{20}$ After the collapse of the Soviet Union, countries in the Commonwealth of Independent States (CIS) attempted to maintain trade with each other, including through establishing a free trade agreement (Michalopoulos and Tarr 1997). In 1996, Russia, Belarus, Kazakhstan, and Kyrgyzstan formed the Eurasian Economic Community with Tajikistan and Uzbekistan joining at a later date. This attempt at a customs union collapsed in failure (Tarr 2016). In 2007, Russia, Belarus,

\footnotetext{
${ }^{19}$ In Equation (A7) in Appendix 2 we have $W_{1}\left(\Gamma^{0}, \boldsymbol{t}\right)>W_{\{1,2\}}\left(\{1,2\}, \boldsymbol{t}^{\prime}\right)-W_{2}\left(\Gamma^{0}, \boldsymbol{t}\right)$ and the long-term payoff with sequential bargaining $\hat{\Pi}^{\text {seq }}$ is greater than either term. It immediately follows that open rule is preferred to sequential bargaining.

${ }^{20}$ For an overview, see Khitakhunov, Mukhamadiyev, and Pomfret (forthcoming).
} 
and Kazakhstan signed the Dushanbe Agreement on the Single Customs Area, which resulted in the formation of the core customs union in 2010. In 2011, the agreement on CIS Free Trade Area was signed, which includes all six original members of the Eurasian Economic Community. In 2015, the Eurasian Economic Union superseded the Eurasian Customs Union, establishing a single economic space. Membership in both unions coincides, and fulfillment of the requirements of the customs union is a precondition for membership in the economic union. Armenia, which was not in the original set of candidates, joined the Eurasian Economic Union in January 2015. After extensive negotiations, Kyrgyzstan signed the accession treaty in May 2015.

While the idea of Eurasian integration is generally attributed to Kazakhstani president Nazarbayev, the Eurasian Union is widely recognized as a Russian-led integration project (Mukhamediyev and Khitakhunov 2016). As the customs union introduced external tariffs mainly at the relatively high Russian level, Russia tends to be the main beneficiary from trade diversion. Reducing delay and non-tariff barriers to trade offers scope for integration gains to customs union membership in addition to free trade agreements (Tarr 2016 and International Monetary Fund 2016). Differences in factor endowments of capital and labor promise further integration gains to creating a single economic space. Additional arguments behind regional integration are transport, mainly in the interest of the landlocked countries of Central Asia, border security (Rumer 2006), and Russia's pre-eminent position in Central Asian energy networks (Wishnick 2011). Despite its economic benefits, the Eurasian Economic Union is often seen as a project that, from Russia's perspective, is mainly political and strategic (Rumer 2006 and Libman 2015): Russia is interested in stability along its borders, containing US influence, counterbalancing the influence of China in the region, and projecting itself as a global power.

Russia is the only country in the region that is in a position to lead the integration process. It has a common history with the other countries in the bloc, it has the largest product and labor markets, it has the financial means to compensate other countries, and its military protection has been an important factor for Armenia: In its border conflict with Azerbaijan over Nagorno-Karabakh, Armenia has been reliant on Russian support. Forming the core customs union had negative externalities on the latecomers Kyrgyzstan, Tajikistan, and Armenia. All suffered declining exports to other CIS countries relative to non-member countries from the region, ${ }^{21}$ which is consistent with the AAH model.

\footnotetext{
${ }^{21}$ Details are available from the authors' online repository.
} 
Because Kyrgyzstan had been a candidate from the outset, its late accession is a particularly compelling case for the study of strategically motivated sequencing. Since the beginning, there were concerns that Kyrgyzstan would lose out economically from customs union membership, in particular from applying the common external tariff (Winner 2013). Its re-export industry and textile industry benefited from a favorable customs regime with the rest of the world, which had made Kyrgyzstan a main entry point for imports into the CIS region, an advantage it was going to lose with accession (Keene 2013). Yet, exclusion from the customs union had a similar detrimental effect that was bound to magnify with the formation of the Eurasian Economic Union and its potential detrimental effect for Kyrgyz migrant workers. So, once the core customs union had formed, for Kyrgyzstan to stay out or to join were comparably bad options, an observation shared by its president Atambaev, who famously declared that accession to the customs union was the "lesser of two evils." 22 Yet, the fact that accession eventually took place suggests that if there had been no external constraints, Russia and Kyrgyzstan could have done at least as well by advancing the settlement. Bargaining frictions offer a potential explanation for the delay. ${ }^{23}$ Bargaining with Atambaev's predecessor, Bakiyev, was hampered by his reluctance to forge closer ties with Russia. After Bakiyev had stepped down in April 2010 following social unrest, the new government, which had won the election on a program of closer ties with Russia, applied for customs union membership within one year (Buckley 2011).

Negotiations on membership were further complicated by Kyrgyzstan's WTO membership. $49 \%$ of Kyrgyz duties were incompatible with those of the customs union and would require renegotiation of WTO terms and possibly compensation to the affected WTO members (Khitakhunov et al. forthcoming). Here, delay offered an automatic adjustment mechanism because with Russia's and Kazakhstan's entry to the WTO, the external tariff of the customs union was going to fall in the medium term. In addition, Kazakhstan was bound to negotiate exemptions from the customs union tariff, strengthening Kyrgyzstan's bargaining position. During negotiations, Kyrgyzstan secured transition periods for 1,500 (of approximately 6,400) products for which the Kyrgyz tariff is lower alongside a Russian grant of 0.2 billion US dollars for modernization of border security and a Russian-Kyrgyz development fund worth 1 billion US dollars set up to mitigate a short-term negative impact of the customs union

\footnotetext{
${ }^{22}$ This dilemma is described by Moldashev (2011) and Pavlov (2012).

${ }^{23}$ Other, possibly not entirely separable, explanations are myopia on the side of the Kyrgyz electorate, uncertainty over political succession, and the need to build the physical infrastructure to support the extended customs union.
} 
membership (International Monetary Fund 2016).

\section{B. Zollverein (German Customs Union)}

As Ploeckl (2010) argued, the strategic situation in Germany in the first half of the $19^{\text {th }}$ century put Prussia in a similarly strong position in the process of forming the German Customs Union (Zollverein). The idea of forming a customs union encompassing all the states of the German Bund was voiced as early as 1819 by Friedrich List in a petition to the German Bundestag in Frankfurt. Moreover, Prussia, as the largest market, was in a natural position to lead and was also the first state to take initial steps with its own customs reforms in 1818.

Different steps in the coalition formation process point to the successful exploitation of coalition externalities by Prussia. A case in point is the accession of Hesse-Cassel in 1831 following the earlier accession of Hesse-Darmstadt. Hesse-Cassel suffered from higher border tariffs imposed by Hesse-Darmstadt and experienced declining living standards, which contributed to civil unrest in $1830 .^{24}$ While Prussia must have preferred the sequential protocol to the multilateral protocol, the question remains why threats were not sufficient to force the outcome. Again, bargaining frictions, the presence of a reluctant incumbent in the case of Hesse-Cassel, may have played a role. Yet, the observation that other German states set up competing unions, such as the Central German Commercial Union of which Hesse-Cassel was a member, suggests that other states believed that building up a counter-threat could strengthen their position. Neither AAH nor our own model considers moves by competing coalitions. So, while the AAH model to some extent explains the formation of Zollverein, its bargaining foundations still deserve further exploration.

\section{Conclusion}

In this study, we have developed a variant of the model of economic integration by

${ }^{24}$ Hesse-Darmstadt had approached Prussia already in 1825 after Prussia’s external tariff had hit its core industries (Mattli 1999). 
Aghion et al (2007) and introduced the option for the agenda setter to select an openrule bargaining protocol, essentially enabling her to threaten an accession candidate with temporary exclusion from customs union rather than having to realize this threat and form the union in sequential steps. We have demonstrated that in such an environment, the time consumed in bargaining is central to the agenda setter's decision of whether to propose sequential formation of customs union and that time-consuming bargaining may incur real costs from unrealized integration gains. The crucial variable is the (incremental) time it takes to negotiate a full settlement under the open-rule protocol relative to the time it takes to form the customs union under sequential integration. In the case of Kyrgyzstan, a long period of time passed before her accession to the Eurasian Customs Union. Yet, given the technical difficulties that needed to be overcome, it is quite plausible that had the initial launch of the customs union depended on Kyrgyzstan, it would have been much more delayed, thereby sacrificing the integration gains from going ahead with forming a core customs union. Our results suggest that as the time spent in negotiating a full settlement approaches the time necessary for the union to form in sequential steps, it is optimal for the agenda setter to choose the sequential bargaining protocol.

In our study, we have treated bargaining time as exogenous, which is appropriate if bargaining is mainly about resolving technical matters. If the distribution of payoffs is at stake, the time needed to form an agreement is likely to depend on the consent of the negotiating parties. In this case, it makes sense to treat as endogenous the time to reach an agreement for both options, i.e., bargaining under an open rule and bargaining over the final accession of the candidate in the case of sequentially forming the customs union. In such a scenario (Alesina and Drazen 1991), the surplus from integration is shared between the agenda setter and the accession candidates, and an agreement is postponed as long as both expect greater concessions by the other party than the cost they incur from continued bargaining. In this case, it would be an advantage for one party to inflict a cost on the other party. This could provide an additional rationale for sequential formation of customs union because under open-rule bargaining, the accession candidate could inflict a cost on the agenda setter by delaying an agreement, whereas under sequential formation of customs union, the accession candidate suffers the externality while bargaining continues. The observation that an agreement on accession into a customs union was reached in time to secure Kyrgyzstan's participation in the Eurasian Economic Union suggests that raising the stakes may help in expediting an agreement.

There are other lessons supported by our case study of Eurasian economic integration: 
When time consumed in bargaining is central to securing efficiency gains, it makes sense for bargainers to look for ways of reducing bargaining-induced costs such as transition rules that facilitate reaching an agreement. Clearly, there are limits to which such rules can be used. Moreover, as our argument above shows, if the distribution of payoffs is an outcome of the bargaining process, there remains some scope for time-consuming bargaining.

Received 17 October 2016, Revised 19 January 2017, Accepted 26 January 2017

\section{References}

Acemoglu, Daron, Georgy Egorov, and Konstantin Sonin. "Dynamics and Stability of Constitutions, Coalitions, and Clubs.” American Economic Review 102 (2012): 1446-76.

Aghion, Phillipe, Pol Antràs, and Elhanan Helpman. "Negotiating Free Trade." Journal of International Economics 73 (2007): 1-30.

Alesina, Alberto and Allan Drazen. "Why Are Stabilizations Delayed?" American Economic Review 81 (1991): 1170-1188.

Baldwin, Richard E. “A Domino Theory of Regionalism.” In Expanding the Membership of the EC, ed. Baldwin, Richard E., Pertti J. Haaparanta, and Jaakko Kiander. Cambridge, MA: Cambridge University Press, 1996.

Baldwin, Richard E. "Sequencing Asian Regionalism.” Journal of Economic Integration 2 (2012): 1-32.

Baron, David and John Ferejohn. "Bargaining in Legislatures." American Political Science Review 83 (1989): 1181-1206.

Buckley, Neil. (2011). 'Foreign policy: Success in 'Near Abroad' is Main Achievement." Financial Times, April 27, 2011. Accessed March 14, 2016, http:/www.ft.com/cms/ s/0/10106c76-6fb5-11e0-952c-00144feabdc0.html.

Gomes, Armando and Philippe Jehiel. "Dynamic Processes of Social and Economic Interactions: On the Persistence of Inefficiencies." Journal of Political Economy 113 
(2005): 626-667.

Furusawa, Taiji and Hideo Konishi. "Free-trade Networks with Transfers." Japanese Economic Review 56 (2005): 144-164.

Furusawa, Taiji and Hideo Konishi. "Free-trade Networks." Journal of International Economics 72 (2007): 310-335.

International Monetary Fund. "Impact of the Accession to the Eurasian Economic Union.” In: Kyrgyz Republic. IMF Country Report 16/56. February 2016.

Keene, Eli. "Growing the Eurasian Customs Union within the WTO." In Carnegie Endowment for International Peace. May 30, 2013. Accessed March 14, 2016, http:// carnegieendowment.org/2013/05/30/growing-eurasian-customs-union-within-wto/g7ee.

Khitakhunov Azimazhan, Bulat Mukhamediyev, and Richard Pomfret. "Eurasian Economic Union: Present and Future Perspectives." Economic Change and Restructuring (forthcoming).

Mattli, Walter. The Logic of Regional Integration. Cambridge, UK: Cambridge University Press, 1999.

Michalopoulis, Constantine and David Tarr. "The Economics of Customs Union in the Commonwealth of Independent States." Post-Soviet Geography and Economics 38 (1997): 125-143.

Moldashev, Kairat. "Joining the Customs Union: The Dilemma of Kyrgyzstan.” Horizon Research, 2011. Accessed March 14, 2016, http://www.horizonresearch.kz/index.php/ru/ analytics-ru/regional-integrations-ru/74-kyrgyzstan-cu.

Mukhamediyev, Bulat and Azimazhan Khitakhunov. "Central Asian Integration and Its Impact on Regional Trade and Economy." In Eurasian Studies in Business and Economics 5, ed. M.H. Bilgin et al., 17-30, Cham, Switzerland: Springer International Publishing, 2016.

Pavlov, Alexander. "Assessing the Economic Effect of Kyrgyzstan's Accession to the Customs Union.” In: Eurasian Integration Yearbook 2012, ed. Evgeny Vinokurov, 6275. Almaty: Eurasian Development Bank, 2012.

Ploeckl, Florian. "The Zollverein and the Formation of a Customs Union." Australian Economic History Review 55 (2015): 277-300. 
Rumer, Eugene B. "China, Russia and the Balance of Power in Central Asia." Strategic Forum 223 (2006): 7-8.

Saggi, Kamal and Halis M. Yildiz. "Bilateral Trade Agreements and the Feasibility of Multilateral Free Trade.” Review of International Economics 81 (2011): 356-373.

Saggi, Kamal, Alan Woodland, and Halis M. Yildiz. "On the Relationship between Preferential and Multilateral Trade Liberalization: The Case of Customs Union." American Economic Journal: Microeconomics 5 (2013): 63-99.

Sen, Neelanjan and Rajit Biswas. "Trade Negotiations under Alternative Bargaining Structure." Economics \& Politics, 27 (2015): 509-523.

Tarr, David G. "The Eurasian Economic Union among Russia, Belarus, Kazakhstan, Armenia and the Kyrgyz Republic: Can It Succeed where Its Predecessors Failed?" Eastern European Economics 54 (2016): 1-22.

Wishnick, Elizabeth. "Russia, China, and the United States in China: Prospects for Great Power Competition and Cooperation in the Shadow of the Georgian Crisis." Current Politics and Economics of Russia, Eastern and Central Europe 26 (2011): 763-808.

Winner, Victor. 'Kyrgyzstan Continues to Weigh 'Pros' and 'Cons' of Joining Customs Union.” Times of Central Asia. May 24, 2013. Accessed September 24, 2013, http://www.timesca.com/index.php/m-news-by-category/politics-analyses-andopinions/10714-kyrgyzstan-continues-to-weigh-pros-and-cons-of-joining-customs$\mathrm{u} \% \mathrm{E} 2 \% 80 \% \mathrm{~A} 6$.

Yi, Sang-Seung. "Endogenous Formation of Customs Union under Imperfect Competition - Open Regionalism is Good." Journal of International Economics 41 (1996): 153-177.

Yi, Sang-Seung. "Stable Coalition Structures with Externalities." Games and Economic Behavior 20 (1997): 201-237.

Yi, Sang-Seung. "Free-trade Areas and Welfare: An Equilibrium Analysis." Review of International Economics 27 (2000): 336-347. 


\section{Appendix 1: Specification of $w(\Gamma, t)$}

We assume that before transfers country $i$ 's decision maker realizes a utility flow

$$
w_{i}(\Gamma, \boldsymbol{t})=v_{i}\left(\boldsymbol{t}_{i}\right)+x_{i}\left(\boldsymbol{t}_{-i}\right)-m_{i}\left(\boldsymbol{t}_{i}\right)+p_{i}(\Gamma)
$$

where $v_{i}$ is consumption benefit excluding consumption of the numeraire good, $x_{i}-m_{i}$ is the trade surplus that is settled by transferring the numeraire good and $p_{i}(\Gamma)$ is a political benefit that $i$ realizes with coalition structure $\Gamma$. $\boldsymbol{t}_{i}$ is a vector of tariffs imposed by country $i$ and $\boldsymbol{t}_{-i}=\left(\boldsymbol{t}_{1}, \ldots, \boldsymbol{t}_{i-1}, \boldsymbol{t}_{i+1}, \ldots, \boldsymbol{t}_{n}\right)$. Building on a continuous goods version of a model by $\mathrm{Yi}$ (1996), Furusawa and Konishi (2005) derived Equation (A1) from a quasi-linear utility function of a consumer who has preferences over a differentiated good. An alternative motivation of Equation (A1) can be given in terms of a political cost function where political pressure exercised by customers and export- and import-substitution industry is proportional to the potential gain or loss that the pressure groups experiences from

a policy change. ${ }^{25}$ The political benefit variable $p_{i}$ captures non-economic motives and is likely to depend only on the coalition of which a country is member. The political benefit of joining a customs union may be negative as it results in a loss of sovereignty or positive as it increases prestige.

\section{Appendix 2: Proof of Proposition 3}

We assume that bargaining for a length of time $s$ delays realization of the long-term payoff $\hat{W}$ by $s$. Let $w^{0}$ be the utility flow in period 1 . Continuous discounting at the rate of time preference $r$ gives

$$
W^{0}=w^{0} \int_{0}^{s} e^{-r t} d t+e^{-r s} \hat{W}, \text { where } w^{0} \int_{0}^{s} e^{-r t} d t=\frac{w^{0}}{r}\left(1-e^{-r s}\right)=W^{0}\left(1-\delta^{s}\right) .
$$

Thus, if the agenda setter makes an offer to 2 first and receives her standalone payoff for a length of time $s$, her expected payoff under open-rule protocol is

$$
\Pi^{O R}=\left(1-\delta^{s}\right) W_{1}\left(\Gamma^{0}, \boldsymbol{t}\right)+\delta^{s}\left[W_{N}\left(\Gamma^{N}, \boldsymbol{t}\right)-W_{2}\left(\Gamma^{0}, \boldsymbol{t}\right)-W_{3}\left(\Gamma^{\prime}, \boldsymbol{t}^{\prime}\right)\right]
$$

\footnotetext{
${ }^{25}$ See Baldwin (2012) for a discussion of how economic integration affects such interests.
} 
Denoting the long-term payoff under sequential bargaining

$$
\hat{\Pi}^{s e q}=W_{N}\left(\Gamma^{N}, \boldsymbol{t}\right)-W_{2}\left(\Gamma^{0}, \boldsymbol{t}^{0}\right)-W_{3}\left(\Gamma^{\prime}, \boldsymbol{t}^{\prime}\right)
$$

we can rewrite Equation (A3) as $\Pi_{1}^{O R}=\left(1-\delta^{s}\right) W_{1}\left(\Gamma^{0}, t^{0}\right)+\delta^{s} \hat{\Pi}^{S e q}$. If the agenda setter makes the initial offer to $\{2,3\}$, she receives the same expected payoff as with multilateral bargaining under a closed-rule protocol. Hence, she prefers making an offer to 2 if

$$
\Pi^{\text {OR }}>\Pi^{\text {Mult }}
$$

where $\Pi^{\text {Mult }}$ is given by Equation (3). ${ }^{26}$ She prefers bargaining under an open-rule protocol with the first offer going to 2 over sequential bargaining if

$$
\Pi^{\text {OR }}>\Pi^{\text {seq }}
$$

where $\Pi^{\text {seq }}$ is given by Equation (4). Using Equation (A6), we can define the difference $\Delta$ by which open-rule bargaining in two steps fares better for the agenda setter than sequential bargaining:

$$
\Delta=\left(\delta^{s}-\delta\right) \hat{\Pi}^{\text {seq }}+\left(1-\delta^{s}\right) W_{1}\left(\Gamma^{0}, t^{0}\right)-(1-\delta)\left[W_{\{1,2\}}\left(\Gamma^{\prime}, \boldsymbol{t}^{\prime}\right)-\mathrm{W}_{2}\left(\Gamma^{0}, \boldsymbol{t}^{0}\right)\right]
$$

Noting that superadditivity implies $W_{1}\left(\Gamma^{0}, \boldsymbol{t}\right) \leq W_{\{1,2\}}\left(\{1,2\}, \boldsymbol{t}^{\prime}\right)-W_{2}\left(\Gamma^{0}, \boldsymbol{t}\right)$, we find that for $\delta<1$ the difference $\Delta$ is negative for $s=1$, i.e., $\Pi_{1}^{s e q}>\Pi_{1}^{O R}$. Because we had assumed negative externalities; hence, $\hat{\Pi}^{\text {seq }}>W_{\{1,2\}}\left(\{1,2\}, \boldsymbol{t}^{\prime}\right)-W_{2}\left(\Gamma^{0}, \boldsymbol{t}^{0}\right)$, the difference is positive for $s=0$ and monotonically decreases for $0<s<1$. This proves that $s^{*}(\delta) \in(0,1)$.

Comparing Equation (A5) and Equation (A6), it is immediate that if the agenda setter prefers open-rule bargaining to sequential bargaining and sequential bargaining to multilateral bargaining, she also prefers the two-step open-rule bargaining procedure which secures $\Pi^{O R}$ to making an offer to the grand coalition that secures a payoff of $\Pi^{\text {Mult }}$. Recall that she prefers sequential over multilateral bargaining when Equation (5) holds or

\footnotetext{
${ }^{26}$ If time to conclude multilateral negotations and time to conclude open rule bargaining coincide, open rule bargaining is always preferred under negative externalities.
} 


$$
\Pi^{\text {seq }}>\Pi^{\text {Mult }}
$$

Hence, for $\delta>\underline{\delta}$, Equation (A6) implies Equation (A5) and for $\delta<\underline{\delta}$, Equation (A5) implies Equation (A6). This proves the last two statements in Proposition 3. We summarize our results in the following graph:

\section{Figure A1. Time preference and length of bargaining round}

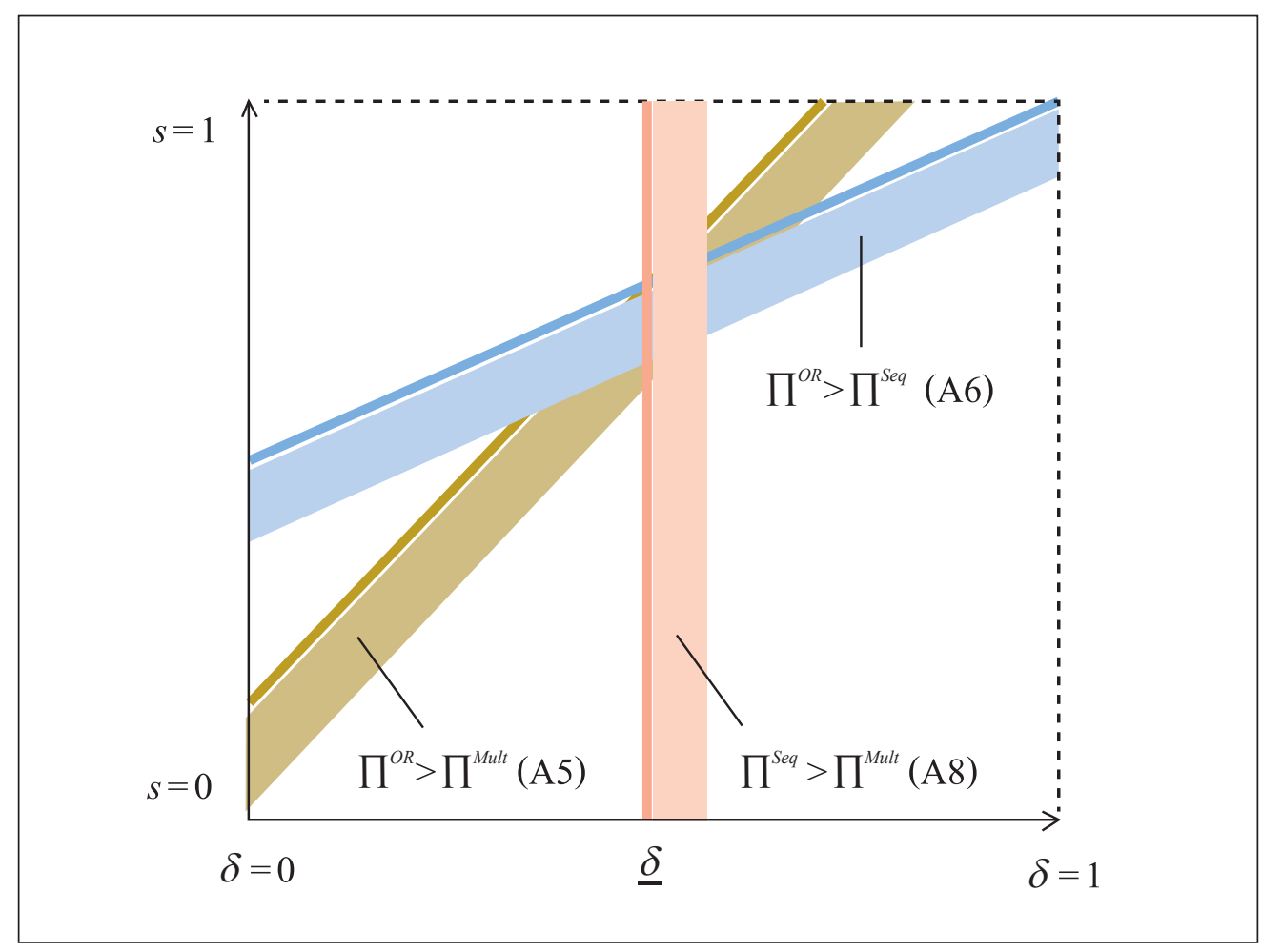

(Note) Figure A1 shows time preference $(\delta)$ and length of bargaining round under the open rule protocol $(s)$ and the agenda setter's preference for sequential, multilateral and two step open-rule bargaining. The shaded areas schematically map the range of parameters $s$ and $\delta$ for which the conditions Equation (A5), Equation (A6), and Equation (A8) are, respectively, fulfilled.

(Source) Authors' creation. 